\title{
Impact of Long-Term Treatment with OROS Methylphenidate on Pubertal Development in Adolescents with ADHD
}

\author{
Paul Hammerness, Daniel Geller, Gagan Joshi, Anna Georgiopoulos, Robert Doyle, \\ Thomas Spencer, Carter Petty, Laura Mahoney, Joseph Biederman \\ Clinical and Research Program in Pediatric Psychopharmacology and Adult ADHD, Massachusetts General \\ Hospital, Boston, USA \\ Email: jbiederman@partners.org
}

Received 19 March 2014; revised 12 April 2014; accepted 20 April 2014

Copyright (C) 2014 by authors and Scientific Research Publishing Inc.

This work is licensed under the Creative Commons Attribution International License (CC BY). http://creativecommons.org/licenses/by/4.0/

(c) (i) Open Access

\begin{abstract}
The objective of this study was to examine whether stimulants impact pubertal development in adolescent Attention Deficit Hyperactivity Disorder (ADHD), an understudied subject. Pubertal staging data were collected during a 2-year open study of extended release methylphenidate in adolescents $(\mathrm{N}=111)$ with ADHD. Tanner stages were compared to national estimates. The sample was primarily male, Caucasian, and a mean age of 14.8 years at baseline. The baseline Tanner stage for $70 \%$ of subjects was consistent with chronological age. For the majority of subjects who reached 12 - 20 months $(\mathrm{N}=25)$ or 24 months $(\mathrm{N}=21)$ endpoints, the Tanner stage at respective endpoints was consistent with age. We found that progression in Tanner stage was not associated with OROS MPH duration or dose ( $p>0.10)$. Long-term treatment with extended release methylphenidate did not appear to adversely impact pubertal development in this sample of adolescents with ADHD.
\end{abstract}

Keywords

Methylphenidate, Puberty, Development, Adolescents, ADHD

\section{Introduction}

Attention Deficit Hyperactivity Disorder (ADHD) is a neurobiological disorder affecting up to $10 \%$ of youth across the world [1] [2]. While generally well tolerated, concerns remain as to whether first line stimulant medications [3] [4] have detrimental effects upon pubertal development. While there has been a resurgence of studies 
regarding stimulants' effects upon height [5], there has been a limited investigation into stimulants' effects on puberty [6] [7].

The main aim of this secondary analysis was to examine the effects of long-term methylphenidate on pubertal development in adolescents with ADHD. To this end, we examined Tanner staging collected during a 24-month prospective study of extended release methylphenidate (OROS MPH). To the best of our knowledge, this is the first prospective evaluation of pubertal development in the context of contemporary stimulant treatment.

\section{Methods}

Detailed study methodology previously described includes a flowchart of study participation [8]. Briefly, subjects were recruited for participation in a study of OROS MPH in adolescents with DSM-IV ADHD. Informed consent and assent were ascertained. Eligible subjects met diagnostic criteria for ADHD by clinical interview with a child and adolescent psychiatrist. The majority of subjects entered the study, self-referred, without a clinically meaningful course of ADHD medication, in terms of dose and duration of treatment; this was not a treatment refractory group. Subjects with clinically significant or unstable medical (e.g., hypertension, diabetes, epilepsy) or psychiatric conditions were excluded. Subjects were active from 2004 to 2011. The study was approved by the hospital Institutional Review Board and registered with ClinicalTrials.gov (NCT00181714).

Following baseline assessments, physicians openly prescribed OROS MPH. Subjects were followed on a weekly basis for six weeks, and monthly thereafter for up to 24 months. OROS MPH doses were clinically adjusted, up to $1.5 \mathrm{mg} / \mathrm{kg} /$ day, based on tolerability and efficacy, according to the ADHD Rating Scale and Clinical Global Impression Scale.

Tanner stages were assigned to genital or breast development (G/B), as well as pubic hair growth (PH); each maturity indicator was rated according to 5 stages [9] [10]. Tanner examinations were performed once during the first six weeks of the study ("Baseline") and approximately every six months thereafter (months 6, 12, 18, and $24,+/-$ one month). Every effort was made for the exam to be performed by a study physician who did not see the subject for regular study visits. Subjects had the option to have this assessment performed by a Primary Care Physician, to self-rate with text descriptions and pictures of Tanner stages consistent with physician ratings, or to refuse the exam. For subjects who discontinued the study before 24-month endpoint, Tanner examinations were completed if more than five months had elapsed since the last exam.

Tanner stages were compared to contemporary estimates of sexual maturation [11] derived from 4263 non-Hispanic white, black, and Mexican American girls and boys aged 8 to 19 years as part of the Third National Health and Nutrition Examination Survey (NHANES III) conducted between 1988 and 1994. As per Sun et al. [11], the median entry age for pubertal development in non-Hispanic white girls is $\sim 10.5$ years old, and boys $\sim 11$ years old.

In this sample, baseline Tanner stages were available in 67 subjects. Change at endpoint was examined in 26 subjects with a baseline exam and $\geq 1$ additional assessment post-baseline. An additional 44 subjects had no baseline exam, but $\geq 1$ exam while on medication (e.g., refused baseline exam).

For analysis at baseline, subjects whose age at the time of Tanner stage evaluation was within (+/-) one standard deviation of the mean for that stage when adjusted for gender and race [11] were deemed "Average" (developing). Those subjects whose baseline age was out of range for Tanner ratings were deemed "Below Average" (age is $>1$ standard deviation above mean; older than expected for Tanner stage) or "Above Average" (age is $<1$ standard deviation below mean; younger than expected for Tanner stage). This approach was used for Tanner stages 2 - 5. For subjects in Tanner stage 1 at baseline, we estimated the age at which $84 \%$ of youth had entered stage 2 as the cutoff consistent with 1 standard deviation from the mean [11]. For example, by age 11, $84 \%$ of African American girls had reached Stage 2; any girl older than that age who hadn't reached Stage 2 was considered "Below Average" [11].

We examined change in Tanner stage for 26 subjects with a Baseline exam and $\geq 1$ additional Tanner assessments post-baseline period (endpoint), including whether change in Tanner stage was significantly associated with OROS MPH duration or dose. In addition, we examined whether Tanner stage at 24 months endpoint was within the expected range per age; this 24 -month pool $(\mathrm{N}=70)$ included 44 subjects without a baseline exam.

\section{Results}

Tanner data were drawn from 111 adolescents with ADHD who were enrolled in the study and who had at least 
one Tanner exam. This sample was primarily male (80\%), Caucasian (90\%), and with a mean age at baseline of 14.8 years (14.6 years boys; 15.2 years girls). Mean OROS MPH exposure was 15 months (endpoint); mean endpoint dose was $59.9 \pm 22.5 \mathrm{mg}(0.95+0.32 \mathrm{mg} / \mathrm{kg} /$ day $)$. A total of 9 genitourinary adverse effects were reported (menstrual cramps, enuresis, increased urination, change in urine color or urine protein); all were deemed unlikely/unrelated to study medication by study physician. Detailed baseline study characteristics as well as adverse events for the primary study have been previously described; adverse effects are consistent with the expected profile of stimulant medications [8].

\subsection{Baseline Tanner Staging}

Using data from Sun et al. [11] as a reference point, Tanner stage for the majority (70\%) of the 67 subjects with baseline exams was consistent with age. For those subjects whose baseline Tanner ratings were lower than expected, immaturity was seen in either G/B or PH ratings; for example, one 13 year old boy with Tanner stage 2 was immature according to $\mathrm{PH}$ rating but within range for $\mathrm{G}$ stage. Four subjects (6\%) were less mature at baseline according to both $\mathrm{G} / \mathrm{B}$ and $\mathrm{PH}$ ratings.

\subsection{Change in Tanner Staging}

Physician rated baseline and endpoint Tanner exams were available for 26 subjects; endpoint exams occurred at a mean of 12 months (boys) and 16 months (girls) after OROS MPH exposure (range 6 - 24 months). At endpoint, Tanner stage was found to have increased 0.2 to 0.8 stages on average for the G/B and PH stages, respectively (Table 1). The majority of G/B ratings in these subjects remained the same (35\%) or increased by one stage (46\%) at endpoint. Similarly, the majority of PH ratings remained the same (42\%) or increased by one stage (39\%) at endpoint. Changes in Tanner stage were not significantly associated with OROS MPH duration or dose (all $\mathrm{p}>0.10$ ). The BMI for this group ( $\mathrm{N}=25 ; \mathrm{N}=1$ without Baseline BMI), was not significantly changed at endpoint $(21.8+/-4.0$ vs. $21.2+/-3.0, t(24)=-1.48, \mathrm{p}=0.15)$.

One subject (13.5 year old boy) did not show Tanner progression during OROS MPH; this subject at baseline was nearly above average for development and at endpoint (24 months) he was in the average range. One subject (14.2 year old boy) had a decline in Tanner stages from baseline to endpoint; this boy's G and PH stages were above average at baseline and average at endpoint (6 months).

\section{Discussion}

This study is the first prospective tracking of pubertal maturation in the context of contemporary stimulant therapy. Overall, subjects' pubertal development was within expected population norms [11], with few outliers observed up to 24 months of exposure. This prospective trial did not find evidence of a negative impact of stimulant duration or dose upon Tanner progression.

For the subset of subjects with baseline and endpoint exams, Tanner stages were found to increase 0.2 to 0.8 stages on average during a mean of 14 months of OROS MPH treatment. This progression of Tanner stage is consistent with expected normal pubertal progression over an approximate one-year time frame [9] [10]. Moreover, we did not find evidence of impact of either dose or duration of OROS MPH treatment upon changes in Tanner staging.

Examining the entire sample, the majority of subjects' Tanner staging was consistent with population norms [11] at baseline and at 12 to 24 month endpoints. A small absolute number of subjects were rated as immature according to pubic and genital development at baseline $(\mathrm{N}=4)$ and at 24-month $(\mathrm{N}=3)$ endpoints. These latter

Table 1. Change in Tanner Stage in Adolescent ADHD Subjects Following Long-term OROS Methylphenidate.

\begin{tabular}{ccccccc}
\hline & \multicolumn{2}{c}{ Baseline } & \multicolumn{2}{c}{ Endpoint } & \multicolumn{2}{c}{ Change at Endpoint } \\
\hline & G/B Stage & PH Stage & G/B Stage & PH Stage & G/B Stage & PH Stage \\
Boys ( $=21)$ & $3.76 \pm 1.09$ & $3.38 \pm 1.32$ & $4.38 \pm 0.74$ & $4.19 \pm 0.87$ & 1.54 & 1.7 \\
Girls ( $=5)$ & $4.00 \pm 1.22$ & $4.20 \pm 1.30$ & $4.20 \pm 1.10$ & $4.60 \pm 0.55$ & 1.04 & 1.29
\end{tabular}

a. Data as Mean \pm St. Deviation; Baseline —initial exam, within 6 weeks of initiating study medication; Endpoint-following mean 16 mos (Boys); 12 mos (Girls) exposure, 24 mos max exposure; G/B Stage—Genital/Breast Stage; PH Stage—Pubic Hair Stage. 
three subjects did not have a baseline Tanner exam to serve as comparison, thus it is not known whether this reflects a change in maturity in the context of stimulant treatment.

Although pubertal assessments were done in the context of rigorous, well-monitored, long-term stimulant treatment for ADHD, the Tanner stage is only one means of assessing pubertal development. Tanner stages were not compared to the Marshall \& Tanner reports [9] [10], as these datasets do not provide adjustment for race or norms for Tanner stage 1. Moreover, the Marshall \& Tanner reports [9] [10] provide normative mean ages based upon reaching a given Tanner stage vs. being in a stage. Overall, this study is limited by its small sample size of primarily boys, lack of comparison group and the fact that genital development at baseline had already progressed for many children. It is possible that earlier exposure to stimulants may have a larger effect on pubertal development.

Given its limitations, this current study is unable to determine whether long-term treatment with OROS methylphenidate has a detrimental effect on sexual maturation in adolescents with ADHD. However, to the best of our knowledge, this is the only prospective report of pubertal maturation in the context of optimized stimulant therapy in adolescents with ADHD. Future larger sample, gender-mixed, controlled studies oriented around pubertal outcomes may be considered.

\section{Acknowledgements}

Data derived from an Investigator Initiated Trial, Janssen Scientific Affairs; Clinical Trial Registration Number: NCT00181714.

\section{Conflicts of Interest}

Paul Hammerness: In the past, Dr. Hammerness has participated in CME activities/professional talks supported by Ortho-McNeil Janssen, Shire and served on the advisory board for Shire. In the past, Dr. Hammerness has participated, as an investigator/principal investigator, in research studies funded by the following pharmaceutical companies: Cephalon, Eli Lilly, Glaxo-SmithKline, Johnson \& Johnson, McNeil, Merck, New River, Novartis, Ortho-McNeil Janssen, Pfizer, Shire, Takeda and Elminda Ltd. Dr. Hammerness has also received honoraria from commercial entities supporting the MGH Psychiatry Academy, www.mghcme.org.

Daniel Geller: In 2012, Dr. Geller received honorarium for speaking/lecture/teaching at AACAP.

Gagan Joshi: Dr. Joshi currently receives support from Forest Research Laboratories and Duke University. Dr. Joshi is also a co-investigator for clinical trials sponsored by Schering-Plough Corporation, Shire, ElMindA, and the U.S. Department of Defense. In 2011, Dr. Joshi received research support from Shire, Johnson \& Johnson Pharmaceutical Research and Development, Eli Lilly, Forest Research Laboratories, Schering-Plough Corporation, ElMindA, and NIMH. In previous years, Dr. Joshi received research support from the following sources: Ethel DuPont Warren Fellowship Award 2005-6; Pilot Research Award from the American Academy of Child and Adolescent Psychiatry 2005; National Institute of Mental Health (Reviewer and member of the NIMH Editorial Board); McNeil Pediatrics (CME sponsored by SynerMed Communications); Bristol Myers Squibb (Site PI for Multi-centered Trial); Glaxo Smith Kline (Site PI for Multi-centered Trial); Shire (Member of national advisory board); Subinvestigator for clinical trials sponsored by Shire, Johnson \& Johnson, Pfizer, Merck, Cephlon, McNeil, Eli-Lily, Abbott, Novartis, Bristol Myers Squibb, Organon, Otsuka, Takeda, \& New River Pharmaceuticals.

Anna Georgiopoulos: Dr. Georgiopoulos received an unrestricted educational grant for a 2005 book published by Lippincott, Williams \& Wilkins from GlaxoSmithKline. She received an honorarium for a Continuing Medical Education (CME) presentation from Pri-Med/Physicians Academy for Clinical and Management Excellence, supported by an educational grant from McNeil Pediatrics, administered by Ortho-McNeil Janssen Scientific Affairs (2009). She received an honorarium for CME presentations from the Harvard Program in Refugee Trauma (2006). She has received travel expense reimbursement and honoraria from the Cystic Fibrosis Foundation (2007-2013). She has been employed by the US Food and Drug Administration for work unrelated to this submission (2010-2012). Her research has been funded by the American Academy of Family Physicians/Minnesota Academy of Family Physicians, the Mayo Foundation, and the US Department of Health and Human Services, and the American Academy of Child and Adolescent Psychiatry. She has participated as Sub-Investigator or Co-Investigator on research studies funded by the following: Bristol Myers Squibb Research Institute, Cephalon, Eli-Lilly \& Co., Elminda, GlaxoSmithKline, Johnson \& Johnson Pharmaceutical Research and De- 
velopment LLC, McNeil Consumer and Specialty Pharmaceuticals, Novartis Pharmaceuticals Corporation, Ortho-McNeil Janssen Scientific Affairs LLC, Shire Development/Shire Pharmaceuticals; as well as NIH-NIMH, NIH-NIDA, NARSAD, the Stanley Foundation, and Harvard Medical School/Massachusetts General Hospital.

Robert Doyle: Dr. Doyle earns honoraria as an instructor and for lecturing in the American Physician Institute Board Review Courses.

Thomas Spencer: Dr. Spencer has received research support from, has been a speaker for or on a speaker bureau, or has been an Advisor or on an Advisory Board of the following sources: Alcobra, Shire Laboratories, Inc, Eli Lilly \& Company, Glaxo-Smith Kline, Janssen Pharmaceutical, McNeil Pharmaceutical, Novartis Pharmaceuticals, Cephalon, Pfizer, the National Institute of Mental Health, and the Department of Defense. Dr. Spencer receives research support from Royalties and Licensing fees on copyrighted ADHD scales through MGH Corporate Sponsored Research and Licensing. Dr. Spencer has a US Patent Application pending (Provisional Number \#61/233,686) through MGH corporate licensing, on a method to prevent stimulant abuse.

Joseph Biederman: Dr. Joseph Biederman is currently receiving research support from the following sources: APSARD, The Department of Defense, ElMindA, Janssen, McNeil, Shire, and Vaya Pharma/Enzymotec. In 2013, Dr. Joseph Biederman received an honorarium from the MGH Psychiatry Academy for a tuition-funded CME course. He has a US Patent Application pending (Provisional Number \#61/233,686) through MGH corporate licensing, on a method to prevent stimulant abuse. Dr. Biederman received departmental royalties from a copyrighted rating scale used for ADHD diagnoses, paid by Shire and Sunovion; these royalties are paid to the Department of Psychiatry at MGH. In 2012, Dr. Joseph Biederman received an honorarium from the MGH Psychiatry Academy and The Children's Hospital of Southwest Florida/Lee Memorial Health System for tuition-funded CME courses. In 2011, Dr. Joseph Biederman gave a single unpaid talk for Juste Pharmaceutical Spain, received honoraria from the MGH Psychiatry Academy for a tuition-funded CME course, and received honoraria for presenting at international scientific conference on ADHD. He also received an honorarium from Cambridge University Press for a chapter publication. Dr. Biederman received departmental royalties from a copyrighted rating scale used for ADHD diagnoses, paid by Eli Lilly, Shire and Astra Zeneca; these royalties are paid to the Department of Psychiatry at MGH. In 2010, Dr. Joseph Biederman received a speaker's fee from a single talk given at Fundación Dr. Manuel Camelo A.C. in Monterrey Mexico. Dr. Biederman provided single consultations for Shionogi Pharma Inc. and Cipher Pharmaceuticals Inc.; the honoraria for these consultations were paid to the Department of Psychiatry at the MGH. Dr. Biederman received honoraria from the MGH Psychiatry Academy for a tuition-funded CME course. In previous years, Dr. Joseph Biederman received research support, consultation fees, or speaker's fees for/from the following additional sources: Abbott, Alza, AstraZeneca, Boston University, Bristol Myers Squibb, Celltech, Cephalon, Eli Lilly and Co., Esai, Fundacion Areces (Spain), Forest, Glaxo, Gliatech, Hastings Center, Janssen, McNeil, Medice Pharmaceuticals (Germany), Merck, MMC Pediatric, NARSAD, NIDA, New River, NICHD, NIMH, Novartis, Noven, Neurosearch, Organon, Otsuka, Pfizer, Pharmacia, Phase V Communications, Physicians Academy, The Prechter Foundation, Quantia Communications, Reed Exhibitions, Shire, the Spanish Child Psychiatry Association, The Stanley Foundation, UCB Pharma Inc., Veritas, and Wyeth.

Carter Petty and Laura Mahoney declare no conflicts of interest.

\section{References}

[1] Visser, S.N., Bitsko, R.H., Danielson, M.L., Perou, R. and Blumberg, S.J. (2010) Increasing Prevalence of Parent-Reported Attention-Deficit/Hyperactivity Disorder among Children-United States 2003-2007. Morbidity and Mortality Weekly Report (MMWR), 59, 1439-1443.

[2] Faraone, S.V., Sergeant, J., Gillberg, C. and Biederman, J. (2003) The Worldwide Prevalence of ADHD: Is It an American Condition? World Psychiatry, 2, 104-113.

[3] Brown, R.T., et al. (2005) Treatment of Attention-Deficit/Hyperactivity Disorder: Overview of the Evidence. Pediatrics, 115, e749-757. http://dx.doi.org/10.1542/peds.2004-2560

[4] Pliszka, S. (2007) Practice Parameter for the Assessment and Treatment of Children and Adolescents with Attention-Deficit/Hyperactivity Disorder. Journal of the American Academy of Child and Adolescent Psychiatry, 46, 894921.

[5] Faraone, S.V., Biederman, J., Morley, C.P. and Spencer, T.J. (2008) Effect of Stimulants on Height and Weight: A Review of the Literature. Journal of the American Academy of Child and Adolescent Psychiatry, 47, 994-1009. http://dx.doi.org/10.1097/CHI.0b013e31817e0ea7 
[6] Poulton, A. (2006) Growth and Sexual Maturation in Children and Adolescents with Attention Deficit Hyperactivity Disorder. Current Opinion in Pediatrics, 18, 427-434. http://dx.doi.org/10.1097/01.mop.0000236394.94827.4c

[7] Spencer, T., et al. (1996) Growth Deficits in ADHD Children Revisited: Evidence for Disorder-Associated Growth Delays? Journal of the American Academy of Child and Adolescent Psychiatry, 35, 1460-1469. http://dx.doi.org/10.1097/00004583-199611000-00014

[8] Hammerness, P., et al. (2013) Do Stimulants Reduce the Risk for Cigarette Smoking in Youth with Attention-Deficit Hyperactivity Disorder? A Prospective, Long-Term, Open-Label Study of Extended-Release Methylphenidate. Journal of Pediatrics, 162, 22-27.

[9] Marshall, W.A. and Tanner, J.M. (1969) Variations in Pattern of Pubertal Changes in Girls. Archives of Disease in Childhood, 44, 291-303. http://dx.doi.org/10.1136/adc.44.235.291

[10] Marshall, W.A. and Tanner, J.M. (1970) Variations in the Pattern of Pubertal Changes in Boys. Archives of Disease in Childhood, 45, 13-23. http://dx.doi.org/10.1136/adc.45.239.13

[11] Sun, S.S., et al. (2002) National Estimates of the Timing of Sexual Maturation and Racial Differences among Us Children. Pediatrics, 110, 911-919. http://dx.doi.org/10.1542/peds.110.5.911 